\title{
OS IMPACTOS DA DOR ONCOLÓGICA EM PACIENTES IDOSOS
}

\author{
Tasla Vieira Soares ${ }^{1}$; Járison Lopes da Silva ${ }^{2}$; Sabrina Alaide Amorim Alves 3
}

Resumo: O câncer configura-se entre as doenças não transmissíveis mais temidas, o qual apresenta incidência consideravelmente aumentada com a idade, devido ao acúmulo de fatores de riscos adquiridos com o passar dos anos. A dor do câncer possui características singulares, que pode ultrapassar seu limiar. Em pacientes idosos oncológicos a dor pode esta associada à privação e ao comprometimento de sua condição de saúde. Diante disso objetivou-se avaliar os impactos da dor oncológica em pacientes idosos. Trata-se de um estudo de revisão sistemática, conduzido conforme a metodologia Preferred Reporting Items for Systematic Reviews and Meta-Analyses (PRISMA). Para identificar os artigos acerca do assunto, realizou-se busca nas bases Medline, Lilacs e a Scientific Eletronic Library - Scielo, PuBMed considerando o período de 1999 a 2015. A busca foi realizada por meio do método integrado, utilizando-se os termos: idosos, dor oncológica, tratamento, câncer. Os critérios de inclusão definidos para a presente revisão foram dor oncológica em pacientes idosos, ser artigos e estar publicado nos idiomas português e inglês. Deste modo, teses de mestrados e carta ao leitor foram exclusos nesse estudo. Foram excluídos estudos cujo desfecho era: artigos que não sejam na língua inglesa e portuguesa, revisão de Literatura, artigos que focassem câncer em criança, adulto, mulheres, artigos que não relatem estudos dos impactos do câncer em pacientes idosos. Dos 110 artigos encontrados, 08 atenderam os critérios de inclusão. Observou que dor oncológica ao adentrar na vida de pacientes idosos traz consigo limitações quanto a suas atividades diárias e que essas são potencializam devido ao fator idade. Privando-o muitas vezes do convívio social, fazendo com que eles se vissem aprisionados pelo câncer e pela dor. Destaca de um olhar ampliado que possa reconhecer sinais de dor, contribuindo para que possa ser ofertada uma atenção integral a esses sujeitos, compreendendo a subjetividade do idoso quanto a vivencia da dor oncológica.

Palavras-chave: Câncer. Dor. Idoso.

\footnotetext{
${ }^{1}$ Discente da Faculdade de Medicina de Juazeiro do Norte-FMJ (Juazeiro do Norte-CE);

${ }^{2}$ Discente da Universidade Federal do Maranhão-UFMA (Maranhão-MA);

${ }^{3}$ Enfermeira pela Faculdade de Juazeiro do Norte-FJN (Juazeiro do Norte-CE); Autor correspondente: tasla_@hotmail.com.
}

50 Id on Line Rev. Mult. Psic. V.12, N. 40. 2018 - ISSN 1981-1179 EDIÇÃO ESPECIAL: I CURSO DE ONCOLOGIA DO CARIRI / II JORNADA DE PESQUISA QUANTI-QUALITATIVA EM ONCOLOGIA. JUAZEIRO DO NORTE, 05 A 10 DE MARÇO DE 2018. Edição eletrônica em http://idonline.emnuvens.com.br/id 